\title{
REVIEW
}

\section{Therapeutic targeting of CK2 in acute and chronic leukemias}

\author{
F Buontempo ${ }^{1}$, JA McCubrey ${ }^{2}$, E Orsini $^{1}$, M Ruzzene ${ }^{3}$, A Cappellini $^{4}$, A Lonetti ${ }^{1}, \mathrm{C}$ Evangelisti ${ }^{5,6}, \mathrm{~F} \mathrm{Chiarini}^{5,6}, \mathrm{C} \mathrm{Evangelisti}^{1}$, \\ JT Barata ${ }^{7}$ and AM Martelli ${ }^{1}$
}

\begin{abstract}
CK2 is a ubiquitously expressed, constitutively active Ser/Thr protein kinase, which is considered the most pleiotropic protein kinase in the human kinome. Such a pleiotropy explains the involvement of CK2 in many cellular events. However, its predominant roles are stimulation of cell growth and prevention of apoptosis. High levels of CK2 messenger RNA and protein are associated with CK2 pathological functions in human cancers. Over the last decade, basic and translational studies have provided evidence of CK2 as a pivotal molecule driving the growth of different blood malignancies. CK2 overexpression has been demonstrated in nearly all the types of hematological cancers, including acute and chronic leukemias, where CK2 is a key regulator of signaling networks critical for cell proliferation, survival and drug resistance. The findings that emerged from these studies suggest that CK2 could be a valuable therapeutic target in leukemias and supported the initiation of clinical trials using CK2 antagonists. In this review, we summarize the recent advances on the understanding of the signaling pathways involved in CK2 inhibition-mediated effects with a particular emphasis on the combinatorial use of CK2 inhibitors as novel therapeutic strategies for treating both acute and chronic leukemia patients.
\end{abstract}

Leukemia (2018) 32, 1-10; doi:10.1038/leu.2017.301

\section{INTRODUCTION}

Phosphorylation can regulate almost every property of a protein and is involved in all fundamental cellular processes. Thus, proper regulation of phosphorylation events is critical to the homeostatic functions of cell signaling. Indeed, deregulation of signaling pathways underlies many human diseases, including cancer. ${ }^{1}$ The importance of phosphorylation makes protein kinases and phosphatases promising therapeutic targets for a wide variety of disorders. ${ }^{2}$ CK2, formerly known as casein kinase II, was discovered in $1954{ }^{3}$ although only recently, and especially over the last two decades, it has become one of the most studied protein kinases, due to its ubiquity, pleiotropy and constitutive activity. In particular, appreciation of its pleiotropy has completely changed our vision of CK2 biology, from an ordinary cell homeostasismaintaining enzyme to a master kinase potentially implicated in many human physiological and pathological events. CK2 is responsible for about $25 \%$ of the phosphoproteome, ${ }^{4}$ as it catalyzes the phosphorylation of $>300$ substrates. $^{5}$ This partly explains the CK2 interconnected roles that underlie its involvement in many signaling pathways. However, CK2 prevalent roles are promotion of cell growth and suppression of apoptosis. Accordingly, several lines of evidence support the notion that CK2 is a key player in the pathogenesis of cancer. High levels of CK2 transcript and protein expression, as well as increased kinase activity are associated with the pathological functions of CK2 in a number of neoplasias. ${ }^{6}$ It was only over the last decade, after extensive analyses in solid tumors, that basic and translational studies have provided evidence for a pivotal role of CK2 in driving the growth of different blood cancers as well, although the first report demonstrating increased CK2 expression in acute myelogenous leukemia (AML) dates back to 1985 . $^{7}$ Since then, CK2 overexpression/activity has been demonstrated in other hematological malignancies, including acute lymphoblastic leukemia (ALL), chronic lymphocytic leukemia (CLL) and chronic myelogenous leukemia $(\mathrm{CML}){ }^{8}$ With the notable exceptions of $\mathrm{CML}$ and pediatric ALL, many patients with leukemias still have a poor outcome, despite the development of protocols with optimized chemotherapy combinations. Insufficient response to first-line therapy and unsalvageable relapses present major therapeutic challenges. Moreover, chemotherapy, even if successful, could have deleterious long-term biological and psychological effects, especially in children. ${ }^{9}$ Furthermore, CML patients can develop resistance to tyrosine kinase inhibitors (TKIs), while both primary chemoresistant and relapsed pediatric ALL cases still remain an unresolved issue. ${ }^{9}$

Therefore, there is a need for novel, less toxic and more effective targeted therapeutic strategies for leukemic patients. The findings that emerged from studies on CK2 in leukemias have highlighted the potential for CK2 inhibitors to be an efficacious treatment for this type of malignant disorders. In this review, following a brief overview of what is known about CK2 in general and its contribution to some aspects of cancer, we will tackle the issue of CK2 inhibitors. Then, we will summarize the recent advances on the signaling pathways involved in CK2 inhibitionmediated effects in leukemias, with a particular emphasis on the combinatorial use of CK2 inhibitors as novel therapeutic strategies.

\footnotetext{
${ }^{1}$ Department of Biomedical and Neuromotor Sciences, University of Bologna, Bologna, Italy; ${ }^{2}$ Department of Microbiology and Immunology, Brody School of Medicine, East Carolina University, Greenville, NC, USA; ${ }^{3}$ Department of Biomedical Sciences, University of Padova, Padova, Italy; ${ }^{4}$ Department of Human, Social and Health Sciences, University of Cassino, Cassino, Italy; ${ }^{5}$ Institute of Molecular Genetics, National Research Council, Bologna, Italy; ${ }^{6}$ Cell and Molecular Biology Laboratory, Rizzoli Orthopedic Institute, Bologna, Italy and ${ }^{7}$ Instituto de Medicina Molecular, Faculdade de Medicina, Universidade de Lisboa, Lisbon, Portugal. Correspondence: Dr JT Barata, Instituto de Medicina Molecular, Faculdade de Medicina da Universidade de Lisboa, Av. Professor Egas Moniz, Lisboa 1649-028, Portugal or Professor AM Martelli, Dipartimento di Scienze Biomediche e Neuromotorie, Università di Bologna, via Irnerio 48, Bologna 40126, Italy.

E-mail: joao_barata@medicina.ulisboa.pt or alberto.martelli@unibo.it

Received 20 July 2017; revised 6 September 2017; accepted 8 September 2017; accepted article preview online 27 September 2017 ; advance online publication, 24 October 2017
} 


\section{CK2 GENERAL FEATURES}

CK2 is ubiquitously distributed in eukaryotes. Its activity depends on the catalytic subunit ( $a$ and/or $a^{\prime}$ ) incorporated into a tetrameric structure (the typical 'butterfly-shaped' holoenzyme) composed of two regulatory $(\beta)$ and two catalytic subunits, in a homozygous or heterozygous composition $\left(a_{2} \beta_{2} ; a a^{\prime} \beta_{2} ; a_{2}^{\prime} \beta_{2}\right)$ (Figure 1). The a subunits comprise a catalytic core consisting of two major folding domains ( $\mathrm{N}$ - and $\mathrm{C}$ - terminal), which harbor the active site in between. ${ }^{10}$ The $\beta$-subunits bind the a-subunits through their C-terminal domains and, by doing so, they enhance the stability, but not the activity, of CK2. Indeed, dimerization of the $\beta$-subunits is mandatory for the holoenzyme. Moreover, the regulatory subunits interact with protein partners and determine substrate specificity. ${ }^{10}$

At variance with most protein kinases whose activity is turned on in response to specific stimuli and whose genetic alterations often underlie pathological situations, CK2 is not susceptible to a tight regulation and there are no gain-of-function mutations known to affect its activity. ${ }^{10}$ CK2a is phosphorylated in a cellcycle-dependent manner at four amino acidic residues located in its C-terminal region. Nevertheless, these phosphorylation events do not affect CK2 catalytic activity. ${ }^{10}$ Also the $\beta$-subunit is phosphorylated at its autophosphorylation site and at Ser 209. ${ }^{10}$ Since autophosphorylation of the $\beta$-subunit controls its stability, this event could result in CK2-enhanced activity, but this hypothesis needs to be investigated in a rigorous manner. Mounting evidence suggests additional mechanisms of CK2 regulation, including polymerization, local recruitment into complexes or intracellular compartmentalization. ${ }^{10}$

Although oncogenic mutations of CK2 have never been reported, its overexpression and hyperactivation are a common denominator in the majority of cancers and are associated with an aggressive tumor cell behavior. ${ }^{11}$ Therefore, the concept of 'cancer addiction' has been recently applied to CK2: cells with abnormally high levels of CK2 are 'predisposed' to malignant transformation and treatment with CK2 inhibitors should deprive them of their refractoriness to apoptosis. ${ }^{12}$ In contrast, CK2 inhibition in healthy cells would result in deprivation of a redundant kinase, so that consequences on cell physiology would be less serious than in cancer cells that are addicted to high CK2 activity levels.

Furthermore, CK2 would create a cellular environment positive to neoplasia not in a classical hierarchical way, but rather by impinging 'laterally' on a number of signaling cascades crucially determining cell fate. ${ }^{13}$

\section{CK2 REGULATION OF CANCER CELL BEHAVIOR}

CK2 acts as a regulator of several hallmarks of cancer cell behavior. ${ }^{1,14}$ For the scope of this review, it is especially important to focus on some signaling networks through which CK2 sustains proliferation and survival of tumor cells.

\section{Sustaining cell proliferation and survival}

CK2 upregulates the PI3K/PTEN/Akt/mTOR, JAK/STAT and Ras/ MEK/ERK signaling modules. These pathways control cell proliferation and survival through multiple mechanisms. ${ }^{15,16}$

CK2 stimulates Akt by two distinct mechanisms. On one side, CK2 phosphorylates a cluster of residues (Ser 380/Thr 382/Ser 385) at the PTEN C-terminal: this stabilizes PTEN but reduces its lipid phosphatase activity, thus preventing the dephosphorylation of phosphatidylinositol 3,4,5-trisphosphate $\left(\mathrm{PIP}_{3}\right)$ and perpetuating its action as Akt activator. ${ }^{17}$ On the other side, CK2 directly phosphorylates Akt at Ser 129, which both positively contributes to Akt activity and increases Akt association with the chaperone protein HSP90, thus protecting Akt from protein phosphatase 2A (PP2A) activity on Thr 308. ${ }^{18}$

As to JAK/STAT, CK2 is an interacting partner of both JAK1 and JAK2, phosphorylates JAK2 in vitro and is essential for JAKSTAT1/3/5 activation, hence it regulates expression of genes which provide survival advantage and proliferative capacity to cancer cells. ${ }^{19-21}$

Regarding the Ras/MEK/ERK module, CK2 potentiates ERK activation by direct phosphorylation at Ser 244/Ser 245/ Ser 246 residues within the nuclear localization signal, thus enhancing ERK $1 / 2$ nuclear translocation and activity. ${ }^{22}$

Another signaling pathway frequently deregulated in cancer cells and displaying both pro-proliferative and anti-apoptotic functions is the NF-KB network. ${ }^{23}$ Functional activation of NF-kB requires it to be released from its inhibitor (IKB) and translocate to the nucleus whereby it activates transcription. This occurs through the regulated degradation of $I_{K} B$, a multistep process in which phosphorylation results in $\mathrm{I} \mathrm{KB}$ ubiquitination and recognition by the proteasome. ${ }^{23}$ CK2 acts a multi-site regulator of the NF-KB signaling pathway. Indeed, CK2 targets not only $\mathrm{lkB}^{24}$ but also both IKK-i/IKKE upstream of $\mathrm{IkB}^{25}$ and NF-KB p65 itself. $^{26}$ Phosphorylation at Ser 529 of p65 enhances the NF-KB transcriptional activity by improving its DNA-binding potential. ${ }^{27}$

Moreover, in addition to the effects on pro-survival signaling pathways, CK2 can directly inhibit both the intrinsic and extrinsic apoptotic pathways, by targeting caspase signaling. ${ }^{28}$
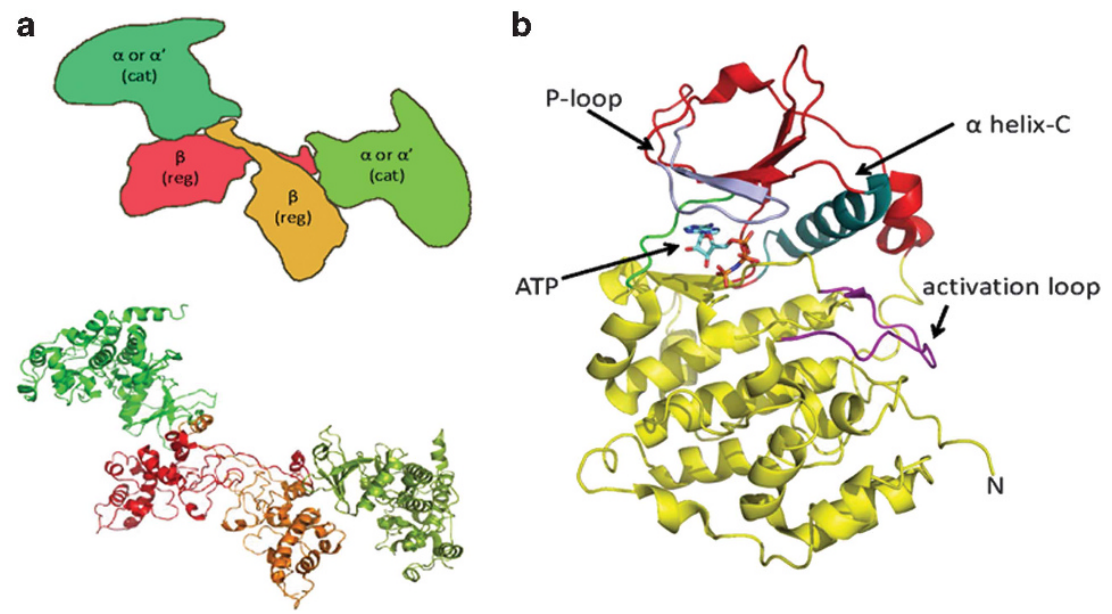

Figure 1. CK2 structure. (a) Schematic representation of the 'butterfly' CK2 heterotetramer (top) and crystal structure (PDB code 1jwh, bottom). (b) Structure of the $\alpha$ catalytic subunit (crystal structure PDB code 1na7), highlighting crucial domains for the constitutive activity. 
a<smiles>OCC1O[C@@H](n2cnc3cc(Cl)c(Cl)cc32)[C@H](O)[C@@H]1O</smiles><smiles>Brc1c(Br)c(Br)c2c(c1Br)N=NNN2</smiles>

TBB<smiles>CN(C)c1nc2c(Br)c(Br)c(Br)c(Br)c2[nH]1</smiles>

DMAT<smiles>O=C(O)c1ccc2c(c1)nc(Nc1cccc(Cl)c1)c1ccncc12</smiles>

CX-4945

\section{b GRKKRRQRRRPPQ $\beta$-ala CWMSPRHLGTC}

\section{CIGB-300}

Figure 2. Selected CK2 inhibitors. (a) DRB (5,6-dichloro-1(b-D-ribofuranosyl)benzimidazole), TBB (4,5,6,7-tetrabromo-2-azabenzimidazole), DMAT (2-dimethylamino-4,5,6,7-tetrabromo-1H-benzimidazole) and CX-4945, all of which are ATP-competitive compounds. (b) CIGB-300 is a peptide, whose primary structure is indicated by one-letter code; sequence in italics corresponds to the cell-penetrating peptide TAT, conjugated to the active moiety by $\beta$-alanine.

Inactivating tumor suppressors

Besides PTEN, CK2 interacts with and phosphorylates p53 at Ser 392 , which results in a partial inactivation of p53 DNA-binding and tumor suppressor functions. ${ }^{29}$ Also PML levels are controlled by CK2 phosphorylation, which promotes its degradation by the proteasome. ${ }^{30}$ Another target of CK2 is Ikaros (IKFZ1). However, as this tumor suppressor is a lymphoid transcription factor of special relevance in ALL, its regulation by CK2 will be discussed in more detail further on in this review.

Regulating endoplasmic reticulum stress/unfolded protein response signaling

Nutrient deprivation, hypoxia, proteasome dysfunction and sustained demands on the secretory pathway are conditions often encountered by cancer cells that can lead to the accumulation of misfolded proteins in the endoplasmic reticulum (ER) and cause 'ER stress'. Unfolded protein response (UPR) encompasses a signaling network that constantly monitors the protein-folding status in the ER and initiates corrective measures for maintaining ER homeostasis. ${ }^{31}$ Recent findings suggest that tumor cells are prone to loss of proteostasis within the ER and that alterations of ER proteostasis are key players in cancer development and aggressiveness. Therefore, cancer cells could be susceptible to targeted drugs that either downregulate homeostatic UPR outputs or alternatively trigger terminal (pro-apoptotic) UPR. $^{32}$ Emerging evidence suggests that CK2 has an important role in the control of ER stress/UPR signaling either by direct protein phosphorylation ${ }^{33}$ or by regulating the transcription of factors involved in ER stress/UPR signaling. ${ }^{34}$

How could CK2 control so many different pathways? An intriguing unifying hypothesis has been proposed. CK2 phosphorylates CDC37 (the co-chaperone of HSP90) at Ser 13. ${ }^{35}$ This phosphorylation strengthens the interactions between CDC37 and HSP90, thereby upregulating the HSP90 chaperoning machinery and increasing the association of HSP90 with client kinases (Akt, ERK, Raf, and so on). This would result in proper folding and maturation of protein kinases that are critical for cancer cells.

\section{CK2 INHIBITORS}

Progress on understanding the multiple roles played by $\mathrm{CK} 2$ has been boosted over the last decades by the availability of several chemical inhibitors (Figure 2). The first ATP-competitive CK2 inhibitor, 5,6-dichloro-1(b-D-ribofuranosyl)benzimidazole (DRB) was disclosed in 1986,36 years after CK2 was discovered by Burnett and Kennedy. ${ }^{3}$ However, a significant improvement in specificity was achieved with the ATP-competitive inhibitor 4,5,6,7-tetrabromo-2-azabenzimidazole (TBB), ${ }^{37}$ which was one of the first CK2 inhibitors used for cell treatment and was shown to induce apoptosis. $^{38}$ 2-dimethylamino-4,5,6,7-tetrabromo-1H-benzimidazole (DMAT) is a derivative of TBB and was demonstrated to have a superior efficacy and similar selectivity for CK2. ${ }^{39}$ However, both TBB and DMAT are effective in cells only at quite high concentrations. Moreover, their specificities are not absolute. ${ }^{40}$

A major progress was represented by the discovery of CX-4945 (Silmitasertib), an orally bioavailable, ATP-competitive CK2 inhibitor that is efficacious in the low micromolar range in cells. ${ }^{41}$ CX-4945 was the first CK2 inhibitor that entered clinical trials for hematological and solid cancer treatment (ClinicalTrials.gov NCT01199718; NCT02128282; NCT00891280).

CIGB-300 is a clinical-stage CK2-specific cell-permeable peptide inhibitor (Figure 2) that modulates CK2 activity by binding to the phosphoacceptor site on CK2 targets. ${ }^{42}$ Although its mechanisms of action are not fully understood and off-target effects have been reported, ${ }^{43}$ CIGB-300 was effective in a variety of cancer cells where it reduced proliferation and induced apoptosis. ${ }^{44}$ Both local and systemic administration of CIGB-300 elicited significant antitumor effects in human cancers xenografted in nude mice. ${ }^{45}$ A phase I clinical trial in cervical cancer showed that CIGB-300 was safe and well tolerated. ${ }^{46}$

\section{CK2 IN ACUTE AND CHRONIC LEUKEMIAS}

Evidence suggests that CK2 has leukemogenic potential, at least in mice. Indeed, transgenic mice with CK2a expression under the control of an immunoglobulin heavy chain promoter and enhancer were prone to develop leukemia/lymphoma, which was accelerated by a c-Myc transgene, resulting in neonatal leukemia. ${ }^{47}$ Moreover, co-expression of CK2a accelerated the development of T-cell ALL (T-ALL)/lymphoma resulting from transgenic expression of the TAL-1 oncogene in the thymus. ${ }^{48}$ Furthermore, p53-deficient CK2a transgenic mice developed thymic lymphomas much faster than their counterpart lacking the CK2 transgene. ${ }^{49}$ Overall, these findings documented that CK2 could be a major player in the oncogenic process, although it is not considered to be a classical oncogene, given the fact that no CK2 gain-of-function mutations have been described so far in cancer patients.

Since then, despite the disparate molecular events that drive the different human leukemia subtypes, high levels of CK2 appeared as a common denominator in all of them, suggesting that CK2 targeting could represent a multi-potential therapeutic strategy. 
Table 1. Targets and functions of CK2 in acute and chronic leukemias

\begin{tabular}{|c|c|c|}
\hline \multirow[t]{4}{*}{ T-ALL } & PTEN & $\begin{array}{l}\text { Phosphorylation, stabilization and inactivation of PTEN lipid phosphatase activity leading to } \\
\text { upregulation of PI3K/Akt/mTOR signaling }\end{array}$ \\
\hline & NOTCH1 signaling & Compensates mutated NOTCH1-driven PTEN transcriptional downregulation ${ }^{59-60}$ \\
\hline & ER stress/UPR signaling & Regulates GRP78/BIP, IRE1 $\alpha$, CHOP expression levels ${ }^{52}$ \\
\hline & 170 kDa P-glycoprotein & Upregulation of expression/activity leading to chemotherapeutic drug resistance ${ }^{62}$ \\
\hline \multirow[t]{3}{*}{$\mathrm{Ph}^{-} \mathrm{B}-\mathrm{ALL}$} & IKFZ-1 & $\begin{array}{l}\text { Downmodulation of tumor suppressor activity, which results in enhanced cell cycle progression and } \\
\text { survival, through the action of multiple genes (CDC25A, CCNA, CCND3, CCNE2, CDK2, CDK6, CDC2, CDC7, } \\
C D C 1, C D C 20, A N A P C 1, A N A P C 17, \text { PIP4KA2, PIK3CD, PIK3CB2, PIKFYVE, PI4KB, PIP4K2B, INPP5D, C-MYC, } \\
\text { MYCBP2, CRLF2, DNM2, BCL6, BACH2, JARID1B) }{ }^{68-74}\end{array}$ \\
\hline & PTEN & $\begin{array}{l}\text { Phosphorylation, stabilization and inactivation of PTEN lipid phosphatase activity leading to } \\
\text { upregulation of } \mathrm{PI} 3 \mathrm{~K} / \mathrm{Akt} / \mathrm{mTOR} \text { signaling } \\
\text { 75 }\end{array}$ \\
\hline & UPR signaling & Activation $^{76}$ \\
\hline $\mathrm{Ph}^{+} \mathrm{B}-\mathrm{ALL}$ & Bcr-Abl & Interacts with the Bcr moiety of both p190 and p210 Bcr-Abl. Stimulates Bcr-Abl activity ${ }^{78-79}$ \\
\hline AML & $\begin{array}{l}\text { PI3K/Akt, NF-KB and STAT3 } \\
\text { signaling networks }\end{array}$ & Potentiates activation of the signaling networks, also in the LIC subset $\left(\mathrm{CD}^{\prime} 4^{+} / \mathrm{CD}^{-} 8^{-} / \mathrm{Lin}^{-}\right)^{81,84}$ \\
\hline \multirow[t]{2}{*}{ CML } & Bcr-Abl & $\begin{array}{l}\text { Physically interacts with Bcr-Abl and enhances protein translation by controlling S6RP phosphorylation } \\
\text { levels, independently from either MEK/ERK1/2 or PI3K/Akt/mTOR signaling }\end{array}$ \\
\hline & PTEN & $\begin{array}{l}\text { Phosphorylation, stabilization and inactivtion of PTEN lipid phosphatase activity leading to enhanced } \\
\text { PI3K/Akt/mTOR signaling }\end{array}$ \\
\hline
\end{tabular}

We will now review the evidence that links CK2 with the pathobiology of both acute and chronic leukemias (summarized in Table 1).

\section{T-ALL}

CK2 acts as a critical regulator of PI3K/Akt/mTOR signaling in T-ALL. This signaling network is overactive in most T-ALL cell lines and patient samples where it portends a poorer prognosis. ${ }^{50}$ It was demonstrated that most pediatric T-ALL patient samples did not harbor PTEN gene alterations, displayed normal PTEN messenger RNA levels and expressed higher PTEN protein levels than normal T-cell precursors, yet $\mathrm{PIP}_{3}$ levels and PI3K/Akt/mTOR signaling were upregulated when compared with healthy thymocyte subsets. ${ }^{51}$ PTEN overexpression was associated with decreased PTEN lipid phosphatase activity, resulting from CK2 overexpression and hyperactivation which targeted several Ser/ Thr residues located at the C-terminal tail of PTEN. Treatment of T-ALL lymphoblasts and cell lines with TBB resulted in abrogation of C-terminal PTEN phosphorylation with concomitant activation of its lipid phosphatase activity and inhibition of Akt phosphorylation. These findings for the first time indicated that aberrant CK2 activity contributed to PI3K/Akt pathway upregulation in T-ALL cells, at least in part, through a PTEN post-translational inactivation. ${ }^{51}$ These results have been subsequently confirmed using the highly selective CK2 inhibitor, CX-4945. ${ }^{52}$

However, very recently, an unanticipated physiological role of CK2 has been disclosed in healthy human $\gamma \delta$ thymocytes. Indeed, $\gamma \delta$ thymocytes displayed higher, and T-cell receptor-inducible, CK2 activity than their $\alpha \beta$ counterparts and were strikingly sensitive to apoptosis upon CK2 pharmacological inhibition. ${ }^{53}$ Nevertheless, CK2 upregulated Akt signaling pathway not only in healthy $\gamma \delta$ thymocytes, but also in $\gamma \delta$ T-ALL cells. When compared with healthy thymocytes or leukemic a $\mathrm{\beta}$ T-cells, $\gamma \delta \mathrm{T}$-ALL cells displayed increased CK2 activity, which was potentiated by CD27 co-stimulation, and enhanced apoptosis upon CK2 blockade by CX-4945. Importantly, CX-4945 was effective in delaying tumor growth in vivo in a xenograft model of human $\gamma \delta$ T-ALL. ${ }^{53}$ Apart from the indication that targeting CK2 could be a therapeutic strategy especially effective for treating T-ALL patients with $\gamma \delta$ lineage blasts that account for about $10 \%$ of total T-ALL cases, these findings are noteworthy for cancer immunotherapy, as $\gamma \delta$ T-cells have been documented to have important roles in protective (anti-tumor) responses. ${ }^{54}$

Recent evidence has highlighted that CK2 is involved in the signals originating from the interleukin (IL)-7 receptor (IL-7R). Both interleukin-7 (IL-7) and its receptor are essential for healthy T-cell development and homeostasis, however aberrant IL-7/IL-7Rmediated signaling promotes and sustains T-ALL. ${ }^{55}$ While IL-7 had a minor but significant positive effect on CK2 activity in leukemic T-cells, CK2 activity was mandatory for optimal IL-7/ IL-7R-dependent signaling. ${ }^{56}$ Indeed, CK2 pharmacological inhibition impaired both JAK1/STAT5 and PI3K/Akt pathway activation triggered by either IL-7 or by mutational activation of IL-7R. As a consequence, viability, growth and cell cycle progression of T-ALL cell lines and lymphoblasts were negatively affected. Furthermore, treatment of IL-7-dependent TAIL7 cells with a combination of CX-4945 and either a pan-JAK inhibitor or the JAK1/2 clinical-stage inhibitor ruxolitinib, synergized in preventing IL-7-mediated viability. Importantly, CK2 activity was required for the viability of T-ALL cells expressing a mutant IL-7R. ${ }^{56}$ Overall, this study identified CK2 as a major effector of IL-7/IL-7R signaling in T-ALL.

NOTCH1 activating mutations have been identified in 50-60\% of T-ALL cases and can be therapeutically targeted with $\mathrm{Y}^{-}$ secretase inhibitors (GSIs). Mutant NOTCH1 can activate both c-MYC and PI3K/Akt signaling in T-ALL. ${ }^{57}$ Indeed, aberrant NOTCH1 signaling could transcriptionally downregulate PTEN expression through HES1 in T-ALL cell lines, thus dampening the efficacy of GSIs. ${ }^{57}$ 
However, it is not entirely clear whether NOTCH1 mutations are associated with decreased PTEN expression in primary T-ALL cells. ${ }^{58}$ It has been reported that, irrespectively of their NOTCH1 mutational status, pediatric T-ALL primary samples expressed significantly higher PTEN protein levels than healthy controls. Nevertheless, NOTCH1-mutated T-ALLs displayed a tendency to have lower PTEN protein levels than NOTCH1-wild-type samples. ${ }^{59}$ GSI treatment upregulated PTEN protein in T-ALL cells, however the increase was paralleled by PTEN phosphorylation at the CK2 target residue Ser 380. These findings suggested that the impact of NOTCH1-mediated PTEN transcriptional downregulation could be partially compensated at the protein level by CK2-dependent PTEN phosphorylation, stabilization and inactivation with a consequent hyperactivation of the PI3K/Akt pathway. Consistently, treatment of NOTCH1-mutated/PTEN-positive T-ALL cell lines and primary samples with both a GSI and a CK2 inhibitor, resulted in a cooperative effect in diminishing leukemic T-cell viability and proliferation. ${ }^{59}$ Therefore, the combination of a GSI with a CK2 inhibitor has the potential to promote PTEN reactivation at both the transcriptional and the post-translational level.

More recently, it has been shown that CK2 blockage synergized in vitro with the bromo- and extra-terminal domain (BET) inhibitor JQ1 in T-ALL cells with upregulated CK2 levels, NOTCH1 activation and high c-Myc expression. ${ }^{60} \mathrm{CX}-4945$ decreased the expression of activated $\mathrm{NOTCH} 1$ by increasing its proteasomal degradation. It should be considered that while CX-4945 induced a pro-apoptotic $\mathrm{UPR}^{52} \mathrm{JQ1}$, by downregulating c-Myc, usually activates a prosurvival UPR. ${ }^{61}$ Therefore, it was hypothesized that CX-4945 and JQ1 could synergistically kill T-ALL cells by switching pro-survival to pro-apoptotic UPR. ${ }^{60}$

Notably, we have shown that CK2 pharmacological inhibition affects UPR in T-ALL cells, as demonstrated by a significant decrease in the levels of the main UPR regulator $78 \mathrm{kDa}$ glucoseregulated protein/binding immunoglobulin protein (GRP78/BIP), and leads to apoptosis via upregulation of the ER stress/UPR cell death mediators inositol-requiring enzyme 1 a (IRE1 a) and CCAATenhancer-binding protein homologous protein (CHOP). ${ }^{52}$ These findings indicate that modulation of the ER stress/UPR signaling through CK2 inhibition may indeed be exploited to induce apoptosis in T-ALL cells.

CK2 could be directly involved in drug resistance of T-ALL cells, as it has been shown that drug-resistant CCRF-CEM cells displayed higher expression levels of the CK2a catalytic subunit when compared to the parental cells. ${ }^{62}$ Drug-resistant CCRF-CEM cells overexpress the membrane transporter $170 \mathrm{kDa}$-glycoprotein (Pgp), encoded by the $A B C B 1$ gene, ${ }^{63}$ one of the major determinants of drug resistance in acute leukemias. Either pharmacological downregulation of CK2 activity or knockdown of CK2a expression by siRNA interference, induced cell death in drug-resistant CCRFCEM cells. Even more importantly, CK2 inhibition promoted an increased uptake of chemotherapeutic drugs inside the leukemic cells and sensitized them to drug-induced apoptosis in a cooperative manner. ${ }^{62}$ The CK2-dependent mechanisms underlying drug resistance remain at present unclear. However, P-gp is a substrate of CK2. ${ }^{64}$ Therefore, the higher amounts of chemotherapeutic drugs accumulated in CCRF-CEM cells when CK2 activity was inhibited, might reflect a positive role had by CK2 in increasing P-gp activity.

Taken together, all of the aforementioned findings will be crucial to rationally develop targeted combination therapies, which include CK2 inhibitors for treating T-ALL patients.

\section{B-ALL}

A growing body of evidence supports the idea that an important function of $\mathrm{CK} 2$ in $\mathrm{Ph}^{-} \mathrm{B}-\mathrm{ALL}$ involves the regulation of the transcription factor, IKZF1. IKZF1 is a tumor suppressor that is crucial for controlling the development and the functions of both B- and T-lymphocytes. ${ }^{65}$

IKZF1 mutations are frequent (20-30\% of cases) in both pediatric and adult B-ALL cases and are associated with a poor patient outcome. ${ }^{66}$ IKZF1 stability and activity are regulated through a fine balance between protein phosphatase 1 (PP1) and CK2 activity. ${ }^{67}$ When phosphorylated by CK2, IKFZ1 displays reduced stability and activity. ${ }^{68}$ These effects could be reversed by PP1. Dovat's group demonstrated that IKFZ1 controls B-ALL cell proliferation by repressing the expression of genes that promote both cell cycle progression and the PI3K/Akt/mTOR pathway. ${ }^{69}$ In a panel of patient-derived primary high-risk B-ALL xenografts, pharmacological inhibition of CK2 restored IKZF1 function as a transcriptional repressor of cell cycle- and PI3K/Akt/mTOR pathway-related genes, resulting in anti-leukemic effects both in vitro and in vivo. Interestingly, in high-risk leukemia where one IKZF1 allele had been deleted, CK2 inhibition restored the transcriptional repressor function of the remaining wild-type IKZF1 allele. $^{69}$

The same group has subsequently shed light on other IKFZ1 functions that are controlled by CK2 in B-ALL cells. These include regulation of the expression of C-MYC (which controls transcription of genes related to cell cycle, survival and metabolism), ${ }^{70}$ MYCBP2 (a putative E3 ubiquitin ligase), ${ }^{70}$ of CRLF2 (a member of the type I cytokine receptor family), ${ }_{1}^{71}$ of DNM2 (a GTPase essential for intracellular vesicle formation and trafficking, cytokinesis and receptor endocytosis), ${ }^{72}$ of $B C L 6$ (a proto-oncogene that is highly expressed in B-ALL) and of $B A C H 2$ (a suppressor of transcription). ${ }^{73}$ Moreover, IKFZ1 repressed transcription of the histone H3K4 demethylase, JARID1B, in B-ALL cells and IKZF1-mediated repression of JARID1B was impaired by CK2. ${ }^{74}$ Indeed, inhibition of CK2 resulted in increased binding of a IKFZ1-HDAC 1 complex to the promoter of JARID1B, with upregulated global levels of trimethylated histone H3 Lys 27 and decreased histone H3 Lys 9 acetylation. $^{74} \mathrm{~A}$ schematic cartoon of CK2/IKFZ1 signaling in $\mathrm{B}-\mathrm{ALL}$ is presented in Figure 3.

Similarly to T-ALL, CK2 phosphorylated and inactivated PTEN in B-ALL cells and this resulted in PI3K/Akt/mTOR activation. ${ }^{75}$ Consistently, CX-4945 reversed PTEN levels to those observed in healthy controls and promoted B-ALL cell death without significantly affecting normal bone marrow cells. ${ }^{75}$

Moreover, we have demonstrated that a combined treatment consisting of bortezomib and CX-4945 prevented B-ALL cells from adequately defending from the ER stress by activating UPR signaling. ${ }^{76}$ In this regard, it is worth remembering that bortezomib recently moved into the pediatric oncology arena, displaying encouraging results in several early phase clinical trials for relapsed B-ALL. ${ }^{77}$

An important role for $\mathrm{CK} 2$ has been identified in $\mathrm{Ph}^{+} \mathrm{B}-\mathrm{ALL}$ where it was found that the a subunit interacts with the $\mathrm{Bcr}$ moiety of both p190 and p210 Bcr-Abl fusion proteins in a region comprised between amino acidic residues 242 and $413 .^{78}$ Treatment of Bcr-Abl ${ }^{+}$leukemic cells with CK2 inhibitors resulted in growth arrest and apoptosis. Apoptosis increased when leukemic cells were treated with a drug combination consisting of DMAT and the TKI, imatinib, ${ }^{78,79}$ while Bcr-Abl inhibition with imatinib resulted in downregulation of CK2 activity. ${ }^{78}$ This observation is interesting since CK2 has always been considered a constitutively active protein kinase, while this report suggests that Bcr-Abl could somehow positively regulate CK2 activity.

Overall, these findings have provided the rational for the use of CK2 inhibitors, either alone or in combination with other drugs already approved (for example, imatinib) or in clinical trials (for example, bortezomib), for B-ALL treatment, including high-risk cases with deletion of one IKZF1 allele or expressing Bcr-Abl. 


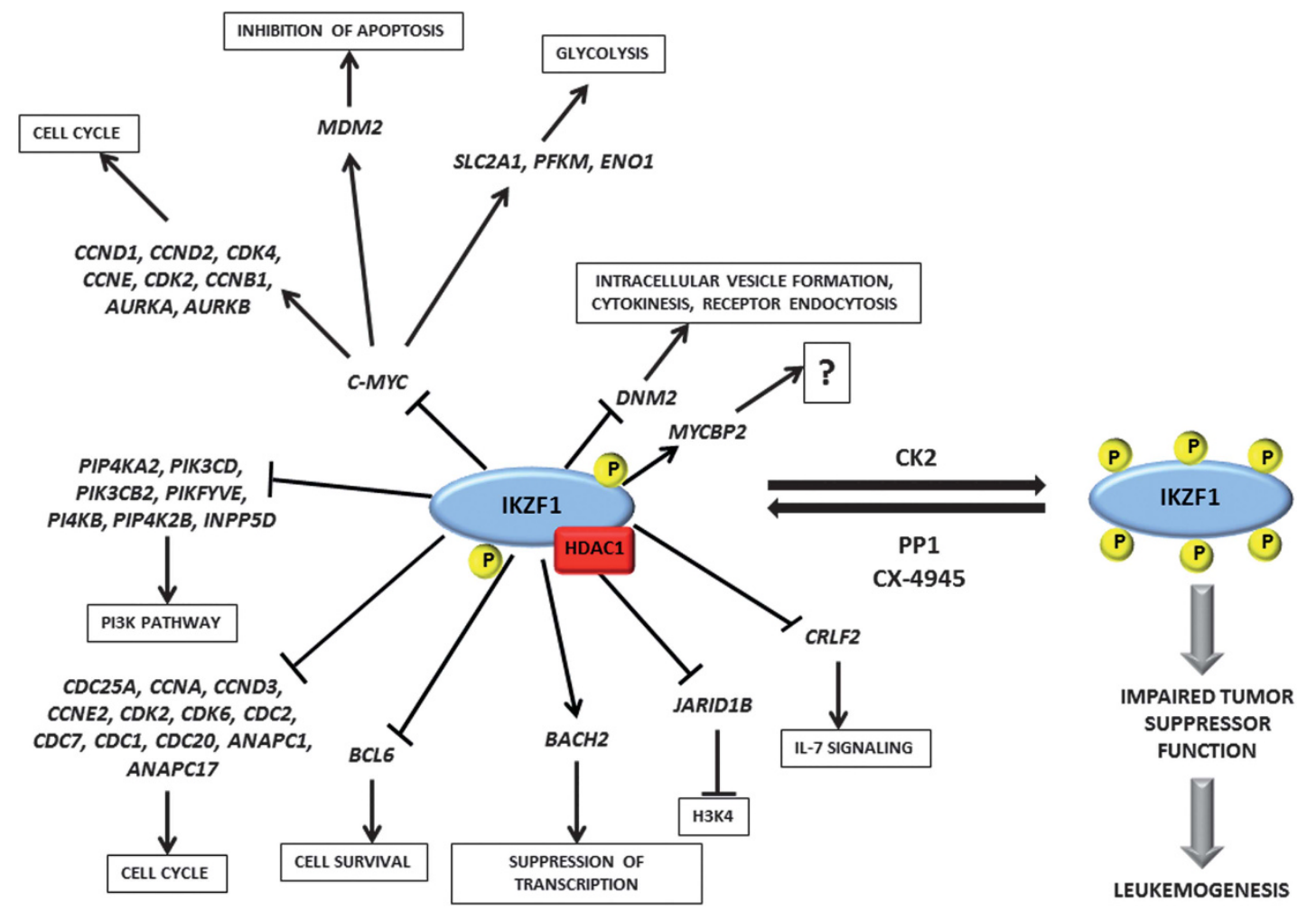

Figure 3. Schematic cartoon of CK2/IKFZ1 signaling in B-ALL. IKFZ1 is a tumor suppressor that controls the transcription of a number of genes critical for the leukemogenic process. CK2 phosphorylates and inactivates IKFZ1 function. The effects of CK2 are counteracted by PP1 and the CK2 inhibitor CX-4945. Arrows indicate activating events; perpendicular lines indicate inhibitory events. HDAC 1, histone deacetylase 1; IKFZ1, Ikaros; PI3K, phosphatidylinositol 3-phosphate kinase; PP1, protein phosphatase 1.

Acute myelogenous leukemia

High-expression levels of CK2a subunit have been linked to a worse prognosis in AML patients with normal karyotype, both in terms of disease-free and overall survival. ${ }^{80}$ Indeed, upregulation of CK2a was associated with increased levels of a number of phosphoproteins belonging to the PI3K/Akt/mTOR pathway, including $\mathrm{Bad}, \mathrm{FoxO} 1, \mathrm{BCl} 2$ and $\mathrm{BCl}-\mathrm{xL}$. Interestingly, overexpression of CK2a in AML cells was paralleled by a decrease in p53 protein levels. Remarkably, CK2 pharmacological inhibitors targeted not only the bulk of leukemic cells, ${ }^{80}$ but also the CD34 ${ }^{+}$ /CD38- AML cell subset, ${ }^{81}$ which is enriched in leukemia-initiating cells (LICs), the true target for leukemia eradication. ${ }^{82}$ CK2 inhibitor effects on LICs were potentiated by concomitant inhibition of PI3K activity, while this treatment had minimal effects on healthy hematopoietic stem cells. ${ }^{81}$ These early studies were subsequently substantiated by findings documenting that either CX-4945 or siRNA to CK2 caused p53-dependent AML cell apoptosis. Furthermore, CK2 inhibition was associated with a synergistic increase of the cytotoxic effects of daunorubicin. ${ }^{83}$

More recently, it has been highlighted that the CK2 catalytic a and regulatory $\beta$ subunits were consistently overexpressed in LICs $\left(\mathrm{CD}_{3}{ }^{+} / \mathrm{CD}^{-} 8^{-} / \mathrm{Lin}^{-}\right)$isolated from a cohort of $\mathrm{AML}$ patients. Analysis of messenger RNA expression showed that CKa expression in LICs was in most cases higher than twofold in comparison with a pool of healthy CD34 ${ }^{+}$hematopoietic stem cells. CK2 inactivation with either CX-4945 or siRNA induced an accumulation of LICs in the late $S / G_{2} / M$ phases of the cell cycle and triggered apoptosis. ${ }^{84}$ Moreover, upon CK2 inhibition, LICs displayed an increased sensitivity to doxorubicin. CK2 blockade was associated with a downmodulation of BMI-1, a protooncogene that is essential for LIC maintenance, ${ }^{85}$ as well as by a marked impairment of activation of Akt, NF-KB and STAT3 signaling. These findings are noteworthy as both Akt and NF-kB play critical roles for LIC biological properties. Importantly, combining CX-4945 and either doxorubicin or NF-KB or STAT3 inhibitors resulted in stronger cytotoxic effects on LICs. ${ }^{84}$ Therefore, this report clearly indicates that CK2 inhibition could be a rational approach to minimize the persistence of residual LICs.

Overall, the studies performed in preclinical models of AML have set the rationale for testing CK2 inhibitors in combination treatments with conventional and/or novel drugs in AML patients.

\section{Chronic lymphocytic leukemia}

A central role for CK2 has been demonstrated in CLL, where CK2 is overexpressed and hyperactive when compared to healthy $\mathrm{B}$ cells. ${ }^{86}$ Chemical inhibition of CK2 induced apoptosis of CLL cells without significantly affecting healthy B- and T-lymphocyte viability. Remarkably, this effect was not reversed by coculturing with OP9 stromal cells, which were otherwise capable of rescuing CLL cells from in vitro spontaneous apoptosis. Upon induction of apoptosis by CK2 inhibition, inactivation of PKC $\beta$ and PKC 8 , two PI3K downstream targets, was reported, which correlated with increased PTEN activity due to dephosphorylation, thus indicating that CK2 regulates CLL cell survival at least in part through phosphorylation-dependent PTEN inactivation and PI3K/ PKC-signaling upregulation. ${ }^{86}$ However, It should be considered that, apart from its role as a negative regulator of the PI3K/Akt/ mTOR pathway, PTEN can localize to the nucleus where it regulates genomic stability and cell proliferation/survival through mechanisms independent from its lipid phosphatase activity. ${ }^{87}$ Nuclear exclusion of PTEN is mediated by ubiquitin-specificprocessing protease 7 (USP7)-dependent de-ubiquitination. Interestingly, CK2 was recently shown to be an upstream positive regulator of USP7 in CLL cells. ${ }^{88}$ A CK2 inhibitor, TBB, promoted PTEN nuclear localization, similarly to the USP7 inhibitor, P5091. 
a

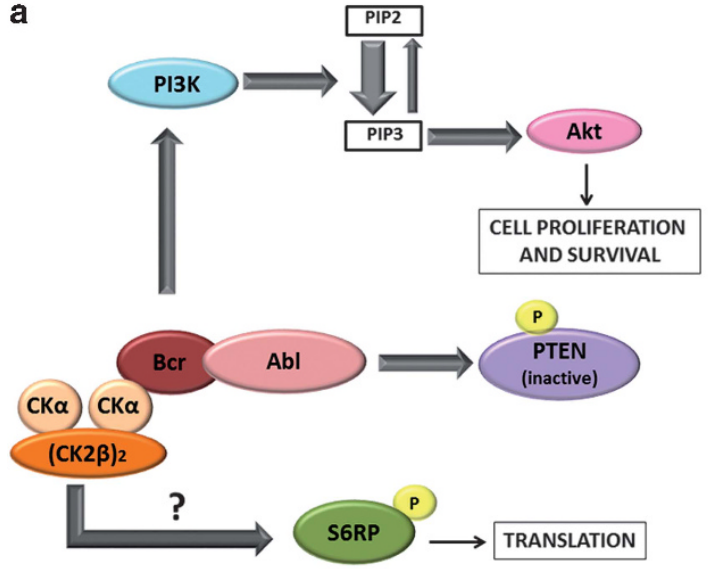

b

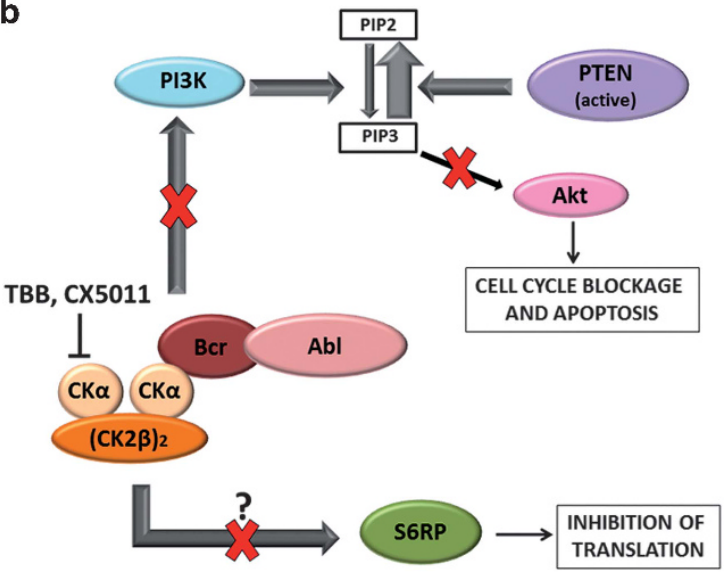

Figure 4. Schematic cartoon of CK2-mediated signaling in CML cells. (a) The Bcr moiety of Bcr-Abl interacts with and activates CK2 which then phosphorylates and inactivates PTEN. Bcr-Abl stimulates PI3K activity on $\mathrm{PIP}_{2}$ that yields $\mathrm{PIP}_{3}$. $\mathrm{PIP}_{3}$ has a fundamental role in Akt activation. Moreover, CK2, through an as yet unclear mechanism, phosphorylates S6RP, which controls translation. (b) Upon treatment with CK2 inhibitors, PI3K activity is dampened and PTEN is able to dephosphosphorylate PIP $_{3}$ to PIP 2 . Therefore, Akt is inhibited. Translation is downregulated due to dephosphorylation of S6RP. Arrows indicate activating events; perpendicular lines indicate inhibitory events. PI3K, phosphatidylinositol 3-phosphate kinase; PIP 2 , phosphatidylinositol 4,5-bisphosphate; PIP $_{3}$, phosphatidylinositol 3,4,5-trisphosphate; S6RP, S6 ribosomal protein; TBB, 4,5,6,7-tetrabromo-2-azabenzimidazole.

Therefore, CK2 targeting could restore not only PTEN lipid phosphatase activity but also its shuttling to the nucleus. Expression of PTEN in the nucleus was associated with cell cycle blockage and induction of apoptosis, confirming the potent oncosuppressive role of PTEN in CLL. ${ }^{88}$

From a mechanistic point of view, it has been recently documented that CK2, complexed in the cytoplasm with CD5 and BLNK (B-cell linker) proteins, phosphorylated STAT3 at Ser 727 in CLL cells. ${ }^{89}$ Ser 727 p-STAT3 has an important role in CLL pathobiology, by activating a series of proliferative and antiapoptotic genes. ${ }^{90}$ Indeed, phosphorylation at Ser 727 confers to STAT3 biologic activities similar to those of tyrosine phosphorylation, as Ser 727 p-STAT3 is shuttled to the nucleus where it binds to DNA and upregulates transcription. ${ }^{90}$ Therefore, STAT3 could be a yet another CK2 key target in CLL.

CK2 antagonists (DRB, TBB) induced apoptosis of CLL cells in all patient samples analyzed, however the sensitivity to CK2 downregulation correlated positively with the percentage of leukemic cells in the peripheral blood, $\beta 2$ microglobulin serum levels and advanced clinical stage. In contrast, sensitivity to CK2 inhibition did not correlate with expression of either ZAP-70 or CD38, or with IGVH mutation status. ${ }^{86}$ These findings suggest that subsets of patients with aggressive CLL may benefit from therapeutic strategies targeting CK2. Subsequent studies, which took advantage of either the clinical-stage CK2 inhibitor, CX-4945, ${ }^{91,92}$ or the cell-permeable peptide, CIGB-300, ${ }^{93}$ confirmed these earlier findings, not only in vitro but also against CLL cells xenografted in mice. Remarkably, CX-4945 was cytotoxic in vitro to samples from patients displaying cytogenetic abnormalities associated with poor outcome and chemotherapy resistance, such as $11 q$ and $17 p$ deletions. ${ }^{92}$ Of note, CX-4945 synergized with either fludarabine or the bruton tyrosine kinase (BTK) inhibitor, ibrutinib, when used in CLL primary cells. ${ }^{91}$ It is worth emphasizing here that ibrutinib is the first-in-class BTK inhibitor approved by the US Food and Drug Administration for treatment of CLL. 94

Overall, all of these investigations indicated that CK2 has important roles in CLL cell survival, paving the ground for the inclusion of CK2 antagonists into future strategies, in combination with traditional chemotherapeutic agents, such as fludarabine, or novel targeted therapies.
Chronic myelogenous leukemia

In 1985, it was documented that CK2 expression was increased in leukemia cells from CML patients in blast crisis, as compared to healthy peripheral blood mononuclear cells. ${ }^{7}$ A subsequent study showed that CKa physically interacts with Bcr-Abl in CML K562 cells via the Abl portion of the fusion protein..$^{95}$ More recently, it was found that in LAMA84 CML cells, characterized by imatinib resistance due to $\mathrm{Bcr}-\mathrm{Abl}$ gene amplification, CK2 protein and catalytic activity were upregulated as compared to imatinibsensitive cells. In resistant cells, CK2 co-localized with Bcr-Abl in the cytoplasm, and these two proteins were members of the same multi-protein complex(es). ${ }^{96}$ Treatment with CX-4945 counteracted the interactions between CK2 and Bcr-Abl and caused cell death by apoptosis. Importantly, a drug combination consisting of CX-4945 and imatinib displayed a synergistic effect in reducing viability of LAMA84 and other resistant CML cell lines, while knockdown of CK2a expression by siRNA restored the sensitivity to low imatinib concentrations. Therefore, these findings demonstrated that CK2 contributes to imatinib resistance in CML cells and suggested that CK2 inhibition could be a promising strategy for combination treatments in CML patients displaying TKIresistance. ${ }^{96}$ Moreover, using imatinib-resistant cell lines, it was found that downregulation of CK2 by either CX-5011 (a CX-4945 derivative) or RNA interference caused a dramatic dephosphorylation of S6 ribosomal protein (S6RP) at Ser 235/236 without affecting MEK/ERK1/2 or PI3K/Akt/mTOR signaling, and concomitant reduction in protein translation. ${ }^{97}$ CK2 pharmacological inhibition induced apoptosis and acted synergistically with either imatinib or a MEK-inhibitor in reducing the viability of imatinibresistant CML cells. These findings highlighted hyperphosphorylation of S6RP as a novel CK2-mediated mechanism of acquired imatinib resistance in CML cells and suggested that co-targeting CK2 and MEK could be another promising drug combination to restore imatinib responsiveness of TKI-resistant CML cells. ${ }^{97}$

In CML cells, Bcr-Abl controlled CK2-dependent PTEN phosphorylation with consequent inactivation of the lipid phosphatase activity. ${ }^{98}$ Accordingly, imatinib treatment reversed the effects of CK2 on PTEN. As expected, CK2 pharmacological targeting promoted PTEN reactivation with concomitant apoptosis induction. Importantly, CK2 inhibition induced apoptosis in imatinibresistant primary CML cells carrying the $\mathrm{T} 315 \mathrm{I}-\mathrm{BCr}-\mathrm{Abl}$ mutation. ${ }^{98}$ 
A schematic cartoon of CK2-dependent signaling in CML is presented in Figure 4.

In light of all of these findings, CK2 signaling has emerged as a potential novel target to achieve synthetic lethality with TKIs, suggesting that a combination therapy could help in eradicating $\mathrm{Ph}^{+}$leukemias even in those cases characterized by TKI-resistance due to Bcr-Abl amplification or mutations.

\section{CONCLUSIONS}

The evidence reviewed here documents that CK2-dependent signals have a central role in the control of leukemia cell proliferation, survival and drug resistance, making CK2 an attractive target for anti-leukemic therapy. These findings have highlighted CK2 inhibitors as novel molecules to be tested in clinical trials aimed at treating both acute and chronic leukemias, although some fundamental outstanding issues still need to be addressed.

In particular, will inhibition of CK2 signaling negatively affect neoplastic blood cells without deleterious side effects on healthy cells? In other words, is there a therapeutic window when such a ubiquitous kinase is to be targeted? The fact that CK2 is often considered as a redundant kinase under normal conditions would suggest that adverse effects could be mild, although definitive evidence is still lacking in humans, whereas in mice, CK2 is required for $\mathrm{CD}^{+}{ }^{\mathrm{T}}$-cell activation and differentiation into either $\mathrm{Th}^{2}$ or $\mathrm{Th}^{17}$ cells. $^{99}$ In this connection, apoptosis elicited by CK2 inhibition in healthy human $\gamma \delta \mathrm{T}$-cells needs to be considered very carefully, although these cells represent a very rare subset (1\%) of total thymocytes. ${ }^{53}$ In an immunocompetent model of glioma in C57BL/6 mice, high doses of CX-4945 produced toxicities, reflected in weight loss and death in one case, with the maximal tolerated established at $600 \mathrm{mg} / \mathrm{kg} .{ }^{100}$ However, whether these data translate to humans is not clear, since the adverse effects elicited by CX-4945 in cancer patients have not been disclosed as yet. It is also worth highlighting that CIGB-300 has been tested by intralesional administration in two phase I cervical cancer clinical trials. Overall, no maximum-tolerated dose or dose-limiting toxicity was observed, and the systemic adverse events were rash, facial edema, itching, hot flashes, and localized cramps, ${ }^{101}$ as well as moderate allergic-like reactions that likely reflected a strong correlation found between unincorporated CIGB-300 and histamine levels in blood. ${ }^{102}$

Importantly, preclinical settings have clearly indicated that the association of CK2 inhibitors with either conventional or novel drugs is likely to offer additional rational therapeutic approaches and a superior efficacy for leukemia treatment. These observations, together with growing preclinical data on the cross-talks between the different signaling cascades controlled by CK2, highlight the importance of a better design of future clinical trials. In particular, correlative or translational sub-studies need to be performed in parallel with the aim to clearly identify clinically feasible and reliable biomarkers of response as well as the emergence of resistance to CK2 inhibition, to guarantee more personalized and effective patient treatments. Future studies aimed to determine additional cell functions that might be regulated by CK2 in leukemias, will be of critical importance for the development of novel and efficacious targeted combination treatments.

\section{CONFLICT OF INTEREST}

The authors declare no conflict of interest.

\section{ACKNOWLEDGEMENTS}

This work was in part supported by a grant (ERC CoG-648455) from the European Research Council, under the European Union's Horizon 2020 research and innovation programme, to JTB, who is also funded by Fundação para a Ciência e a Tecnologia (FCT investigator and FAPESP/20015/2014). We apologize to the authors whose work, although of importance, may have not been included in this review due to space constrains.

\section{REFERENCES}

1 Hanahan D, Weinberg RA. Hallmarks of cancer: the next generation. Cell 2011; 144: 646-674.

2 Cohen P. Protein kinases--the major drug targets of the twenty-first century? Nat Rev Drug Discov 2002; 1: 309-315.

3 Burnett G, Kennedy EP. The enzymatic phosphorylation of proteins. J Biol Chem 211: 969-980.

4 Venerando A, Ruzzene M, Pinna LA. Casein kinase: the triple meaning of a misnomer. Biochem J 2014; 460: 141-156.

5 Meggio F, Pinna LA. One-thousand-and-one substrates of protein kinase CK2? FASEB J 2003; 17: 349-368.

6 Trembley JH, Wang G, Unger G, Slaton J, Ahmed K. Protein kinase CK2 in health and disease: CK2: a key player in cancer biology. Cell Mol Life Sci 2009; 66: 1858-1867.

7 Phan-Dinh-Tuy F, Henry J, Boucheix C, Perrot JY, Rosenfeld C, Kahn A. Protein kinases in human leukemic cells. Am J Hematol 1985; 19: 209-218.

8 Mandato E, Manni S, Zaffino F, Semenzato G, Piazza F. Targeting CK2-driven nononcogene addiction in B-cell tumors. Oncogene 2016; 35: 6045-6052.

9 Carroll WL, Hunger SP. Therapies on the horizon for childhood acute lymphoblastic leukemia. Curr Opin Pediatr 2016; 28: 12-18.

10 Gowda C, Sachdev M, Muthusami S, Kapadia M, Petrovic-Dovat L, Hartman M et al. Casein kinase II (CK2) as a therapeutic target for hematological malignancies. Curr Pharm Des 2017; 23: 95-107.

11 Ortega CE, Seidner Y, Dominguez I. Mining CK2 in cancer. PLoS One 2014; 9: e115609.

12 Ruzzene M, Tosoni K, Zanin S, Cesaro L, Pinna LA. Protein kinase CK2 accumulation in "oncophilic" cells: causes and effects. Mol Cell Biochem 2011; 356: 5-10.

13 Piazza F, Manni S, Ruzzene M, Pinna LA, Gurrieri C, Semenzato G. Protein kinase CK2 in hematologic malignancies: reliance on a pivotal cell survival regulator by oncogenic signaling pathways. Leukemia 2012; 26: 1174-1179.

14 Trembley JH, Chen Z, Unger G, Slaton J, Kren BT, Van Waes C et al. Emergence of protein kinase CK2 as a key target in cancer therapy. Biofactors 2010; 36: 187-195.

15 McCubrey JA, Steelman LS, Abrams SL, Bertrand FE, Ludwig DE, Basecke J et al. Targeting survival cascades induced by activation of Ras/Raf/MEK/ERK, PI3K/ PTEN/Akt/mTOR and Jak/STAT pathways for effective leukemia therapy. Leukemia 2008; 22: 708-722.

16 Steelman LS, Abrams SL, Whelan J, Bertrand FE, Ludwig DE, Basecke J et al. Contributions of the Raf/MEK/ERK, PI3K/PTEN/Akt/mTOR and Jak/STAT pathways to leukemia. Leukemia 2008; 22: 686-707.

17 Torres J, Pulido R. The tumor suppressor PTEN is phosphorylated by the protein kinase CK2 at its C terminus. Implications for PTEN stability to proteasomemediated degradation. J Biol Chem 2001; 276: 993-998.

18 Di Maira G, Brustolon F, Pinna LA, Ruzzene M. Dephosphorylation and inactivation of Akt/PKB is counteracted by protein kinase CK2 in HEK 293T cells. Cell Mol Life Sci 2009; 66: 3363-3373.

19 Zheng Y, Qin H, Frank SJ, Deng L, Litchfield DW, Tefferi A et al. A CK2-dependent mechanism for activation of the JAK-STAT signaling pathway. Blood 2011; 118: 156-166.

20 Zheng Y, McFarland BC, Drygin D, Yu H, Bellis SL, Kim H et al. Targeting protein kinase CK2 suppresses prosurvival signaling pathways and growth of glioblastoma. Clin Cancer Res 2013; 19: 6484-6494.

21 Gray GK, McFarland BC, Rowse AL, Gibson SA, Benveniste EN. Therapeutic CK2 inhibition attenuates diverse prosurvival signaling cascades and decreases cell viability in human breast cancer cells. Oncotarget 2014; 5: 6484-6496.

22 Schevzov G, Kee AJ, Wang B, Sequeira VB, Hook J, Coombes JD et al. Regulation of cell proliferation by ERK and signal-dependent nuclear translocation of ERK is dependent on Tm5NM1-containing actin filaments. Mol Biol Cell 2015; 26: 2475-2490.

23 Yu L, Li L, Medeiros LJ, Young KH. NF-KB signaling pathway and its potential as a target for therapy in lymphoid neoplasms. Blood Rev 2017; 31: 77-92.

24 Chu ZL, McKinsey TA, Liu L, Qi X, Ballard DW. Basal phosphorylation of the PEST domain in the IKB $\beta$ regulates its functional interaction with the c-rel protooncogene product. Mol Cell Biol 1996; 16: 5974-5984.

25 Eddy SF, Guo S, Demicco EG, Romieu-Mourez R, Landesman-Bollag E, Seldin DC et al. Inducible IKB kinase/IKB kinase $\varepsilon$ expression is induced by $\mathrm{CK} 2$ and promotes aberrant nuclear factor- $\mathrm{KB}$ activation in breast cancer cells. Cancer Res 2005; 65: 11375-11383. 
26 Chantome A, Pance A, Gauthier N, Vandroux D, Chenu J, Solary E et al. Casein kinase II-mediated phosphorylation of NF-KB p65 subunit enhances inducible nitric-oxide synthase gene transcription in vivo. J Biol Chem 2004; 279: 23953-23960.

27 Wang D, Richmond A. Nuclear factor- $\mathrm{B} B$ activation by the CXC chemokine melanoma growth-stimulatory activity/growth-regulated protein involves the MEKK1/p38 mitogen-activated protein kinase pathway. J Biol Chem 2001; 276: 3650-3659.

28 Duncan JS, Turowec JP, Duncan KE, Vilk G, Wu C, Luscher B et al. A peptidebased target screen implicates the protein kinase CK2 in the global regulation of caspase signaling. Sci Signal 2011; 4: ra30.

29 Cox ML, Meek DW. Phosphorylation of serine 392 in p53 is a common and integral event during p53 induction by diverse stimuli. Cell Signal 2010; 22: 564-571.

30 Scaglioni PP, Yung TM, Cai LF, Erdjument-Bromage H, Kaufman AJ, Singh B et al. A CK2-dependent mechanism for degradation of the PML tumor suppressor. Cell 2006; 126: 269-283.

31 Oakes SA. Endoplasmic reticulum proteostasis: a key checkpoint in cancer. Am J Cell Physiol Cell Physiol 2017; 312: C93-C102.

32 Galmiche A, Sauzay C, Chevet E, Pluquet O. Role of the unfolded protein response in tumor cell characteristics and cancer outcome. Curr Opin Oncol 2017; 29: 41-47.

33 Ampofo E, Sokolowsky T, Gotz C, Montenarh M. Functional interaction of protein kinase CK2 and activating transcription factor 4 (ATF4), a key player in the cellular stress response. Biochim Biophys Acta 2013; 1833: 439-451.

34 Schneider CC, Ampofo E, Montenarh M. CK2 regulates ATF4 and CHOP transcription within the cellular stress response signalling pathway. Cell Signal 2012; 24: 1797-1802.

35 Miyata Y, Nishida E. CK2 controls multiple protein kinases by phosphorylating a kinase-targeting molecular chaperone, Cdc37. Mol Cell Biol 2004; 24: 4065-4074.

36 Zandomeni R, Zandomeni MC, Shugar D, Weinmann R. Casein kinase type II is involved in the inhibition by 5,6-dichloro-1- $\beta$-D-ribofuranosylbenzimidazole of specific RNA polymerase II transcription. J Biol Chem 1986; 261: 3414-3419.

37 Sarno S, Reddy H, Meggio F, Ruzzene M, Davies SP, Donella-Deana A et al. Selectivity of 4,5,6,7-tetrabromobenzotriazole, an ATP site-directed inhibitor of protein kinase CK2 ('casein kinase-2'). FEBS Lett 2001; 496: 44-48.

38 Ruzzene M, Penzo D, Pinna LA. Protein kinase CK2 inhibitor 4,5,6,7-tetrabromobenzotriazole (TBB) induces apoptosis and caspase-dependent degradation of haematopoietic lineage cell-specific protein 1 (HS1) in Jurkat cells. Biochem J 2002; 364: 41-47.

39 Pagano MA, Meggio F, Ruzzene M, Andrzejewska M, Kazimierczuk Z, Pinna LA. 2Dimethylamino-4,5,6,7-tetrabromo-1H-benzimidazole: a novel powerful and selective inhibitor of protein kinase CK2. Biochem Biophys Res Commun 2004; 321: 1040-1044.

40 Pagano MA, Bain J, Kazimierczuk Z, Sarno S, Ruzzene M, Di Maira G et al. The selectivity of inhibitors of protein kinase CK2: an update. Biochem J 2008; 415: 353-365.

41 Siddiqui-Jain A, Drygin D, Streiner N, Chua P, Pierre F, O'Brien SE et al. CX-4945, an orally bioavailable selective inhibitor of protein kinase $\mathrm{CK} 2$, inhibits prosurvival and angiogenic signaling and exhibits antitumor efficacy. Cancer Res 2010; 70: 10288-10298.

42 Perea SE, Reyes O, Puchades Y, Mendoza O, Vispo NS, Torrens I et al. Antitumor effect of a novel proapoptotic peptide that impairs the phosphorylation by the protein kinase 2 (casein kinase 2). Cancer Res 2004; 64: 7127-7129.

43 Zanin S, Sandre M, Cozza G, Ottaviani D, Marin O, Pinna LA et al. Chimeric peptides as modulators of CK2-dependent signaling: mechanism of action and off-target effects. Biochim Biophys Acta 2015; 1854: 1694-1707.

44 Perea SE, Reyes O, Baladron I, Perera Y, Farina H, Gil J et al. CIGB-300, a novel proapoptotic peptide that impairs the CK2 phosphorylation and exhibits anticancer properties both in vitro and in vivo. Mol Cell Biochem 2008; 316: 163-167.

45 Perera Y, Farina HG, Hernandez I, Mendoza O, Serrano JM, Reyes O et al. Systemic administration of a peptide that impairs the protein kinase (CK2) phosphorylation reduces solid tumor growth in mice. Int $J$ Cancer 2008; 122: 57-62.

46 Perea SE, Baladron I, Garcia Y, Perera Y, Lopez A, Soriano JL et al. CIGB-300, a synthetic peptide-based drug that targets the CK2 phosphoaceptor domain. Translational and clinical research. Mol Cell Biochem 2011; 356: 45-50.

47 Seldin DC, Leder P. Casein kinase II a transgene-induced murine lymphoma: relation to theileriosis in cattle. Science 1995; 267: 894-897.

48 Kelliher MA, Seldin DC, Leder P. Tal-1 induces T cell acute lymphoblastic leukemia accelerated by casein kinase Ila. EMBO J 1996; 15: 5160-5166.

49 Landesman-Bollag E, Channavajhala PL, Cardiff RD, Seldin DC. p53 deficiency and misexpression of protein kinase CK2a collaborate in the development of thymic lymphomas in mice. Oncogene 1998; 16: 2965-2974.
50 Evangelisti C, Chiarini F, Lonetti A, Buontempo F, Bressanin D, Cappellini A et al. Therapeutic potential of targeting mTOR in T-cell acute lymphoblastic leukemia. Int J Oncol 2014; 45: 909-918.

51 Silva A, Yunes JA, Cardoso BA, Martins LR, Jotta PY, Abecasis M et al. PTEN posttranslational inactivation and hyperactivation of the PI3K/Akt pathway sustain primary T cell leukemia viability. J Clin Invest 2008; 118: 3762-3774.

52 Buontempo F, Orsini E, Martins LR, Antunes I, Lonetti A, Chiarini F et al. Cytotoxic activity of the casein kinase 2 inhibitor CX-4945 against T-cell acute lymphoblastic leukemia: targeting the unfolded protein response signaling. Leukemia 2014; 28: 543-553.

53 Ribeiro ST, Tesio M, Ribot JC, Macintyre E, Barata JT, Silva-Santos B. Casein kinase 2 controls the survival of normal thymic and leukemic $\gamma \delta$ T cells via promotion of AKT signaling. Leukemia 2017; 31: 1603-1610.

54 Silva-Santos B, Serre K, Norell H. $ү \delta$ T cells in cancer. Nat Rev Immunol 2015; 15: 683-691.

55 Silva A, Laranjeira AB, Martins LR, Cardoso BA, Demengeot J, Yunes JA et al. IL-7 contributes to the progression of human T-cell acute lymphoblastic leukemias. Cancer Res 2011; 71: 4780-4789.

56 Melao A, Spit M, Cardoso BA, Barata JT. Optimal interleukin-7 receptor-mediated signaling, cell cycle progression and viability of T-cell acute lymphoblastic leukemia cells rely on casein kinase 2 activity. Haematologica 2016; 101: 1368-1379.

57 Hales EC, Taub JW, Matherly LH. New insights into Notch1 regulation of the PI3KAKT-mTOR1 signaling axis: targeted therapy of $\gamma$-secretase inhibitor resistant T-cell acute lymphoblastic leukemia. Cell Signal 2014; 26: 149-161.

58 Palomero T, Sulis ML, Cortina M, Real PJ, Barnes K, Ciofani M et al. Mutational loss of PTEN induces resistance to NOTCH1 inhibition in T-cell leukemia. Nat Med 2007; 13: 1203-1210.

59 Silva A, Jotta PY, Silveira AB, Ribeiro D, Brandalise SR, Yunes JA et al. Regulation of PTEN by CK2 and Notch1 in primary T-cell acute lymphoblastic leukemia: rationale for combined use of CK2- and $\gamma$-secretase inhibitors. Haematologica 2010; 95: 674-678.

60 Lian H, Li D, Zhou Y, Landesman-Bollag E, Zhang G, Anderson NM et al. CK2 inhibitor CX-4945 destabilizes NOTCH1 and synergizes with JQ1 against human T-acute lymphoblastic leukemic cells. Haematologica 2017; 102: e17-e21.

61 Hart LS, Cunningham JT, Datta T, Dey S, Tameire F, Lehman SL et al. ER stressmediated autophagy promotes Myc-dependent transformation and tumor growth. J Clin Invest 2012; 122: 4621-4634.

62 Di Maira G, Brustolon F, Bertacchini J, Tosoni K, Marmiroli S, Pinna LA et al. Pharmacological inhibition of protein kinase CK2 reverts the multidrug resistance phenotype of a CEM cell line characterized by high CK2 level. Oncogene 2007; 26: 6915-6926.

63 Mantovani I, Cappellini A, Tazzari PL, Papa V, Cocco L, Martelli AM. Caspasedependent cleavage of $170-\mathrm{kDa}$ P-glycoprotein during apoptosis of human T-lymphoblastoid CEM cells. J Cell Physiol 2006; 207: 836-844.

64 Glavy JS, Horwitz SB, Orr GA. Identification of the in vivo phosphorylation sites for acidic-directed kinases in murine mdr1b P-glycoprotein. J Biol Chem 1997; 272: 5909-5914.

65 Yoshida T, Georgopoulos K. Ikaros fingers on lymphocyte differentiation. Int J Hematol 2014; 100: 220-229.

66 Olsson L, Johansson B. Ikaros and leukaemia. Br J Haematol 2015; 169: 479-491.

67 Wang H, Song C, Gurel Z, Song N, Ma J, Ouyang H et al. Protein phosphatase 1 (PP1) and casein kinase II (CK2) regulate lkaros-mediated repression of TdT in thymocytes and T-cell leukemia. Pediatr Blood Cancer 2014; 61: 2230-2235.

68 Song C, Li Z, Erbe AK, Savic A, Dovat S. Regulation of Ikaros function by casein kinase 2 and protein phosphatase 1. World J Biol Chem 2011; 2: 126-131.

69 Song C, Gowda C, Pan X, Ding Y, Tong Y, Tan BH et al. Targeting casein kinase II restores Ikaros tumor suppressor activity and demonstrates therapeutic efficacy in high-risk leukemia. Blood 2015; 126: 1813-1822.

70 Ge Z, Guo X, Li J, Hartman M, Kawasawa YI, Dovat S et al. Clinical significance of high C-MYC and low MYCBP2 expression and their association with Ikaros dysfunction in adult acute lymphoblastic leukemia. Oncotarget 2015; 6 : 42300-42311.

71 Ge Z, Gu Y, Zhao G, Li J, Chen B, Han Q et al. High CRLF2 expression associates with IKZF1 dysfunction in adult acute lymphoblastic leukemia without CRLF2 rearrangement. Oncotarget 2016; 7: 49722-49732.

72 Ge Z, Gu Y, Han Q, Zhao G, Li M, Li J et al. Targeting high dynamin-2 (DNM2) expression by restoring Ikaros function in acute lymphoblastic leukemia. Sci Rep 2016; 6: 38004

73 Ge Z, Zhou X, Gu Y, Han Q, Li J, Chen B et al. Ikaros regulation of the BCL6/BACH2 axis and its clinical relevance in acute lymphoblastic leukemia. Oncotarget 2017; 8: 8022-8034.

74 Wang H, Song C, Ding Y, Pan X, Ge Z, Tan BH et al. Transcriptional regulation of JARID1B/KDM5B histone demethylase by lkaros, histone deacetylase 1 (HDAC1), and casein kinase 2 (CK2) in B-cell acute lymphoblastic leukemia. J Biol Chem 2016; 291: 4004-4018. 
75 Gomes AM, Soares MV, Ribeiro P, Caldas J, Povoa V, Martins LR et al. Adult B-cell acute lymphoblastic leukemia cells display decreased PTEN activity and constitutive hyperactivation of PI3K/Akt pathway despite high PTEN protein levels. Haematologica 2014; 99: 1062-1068.

76 Buontempo F, Orsini E, Lonetti A, Cappellini A, Chiarini F, Evangelisti C et al. Synergistic cytotoxic effects of bortezomib and CK2 inhibitor CX-4945 in acute lymphoblastic leukemia: turning off the prosurvival ER chaperone BIP/Grp78 and turning on the pro-apoptotic NF-kappaB. Oncotarget 2016; 7: 1323-1340.

77 Citrin R, Foster JB, Teachey DT. The role of proteasome inhibition in the treatment of malignant and non-malignant hematologic disorders. Exp Rev Hematol 2016; 9: 873-889.

78 Mishra S, Reichert A, Cunnick J, Senadheera D, Hemmeryckx B, Heisterkamp N et al. Protein kinase CKIla interacts with the Bcr moiety of Bcr/Abl and mediates proliferation of Bcr/Abl-expressing cells. Oncogene 2003; 22: 8255-8262.

79 Mishra S, Pertz V, Zhang B, Kaur P, Shimada H, Groffen J et al. Treatment of P190 $\mathrm{Bcr} / \mathrm{Abl}$ lymphoblastic leukemia cells with inhibitors of the serine/threonine kinase CK2. Leukemia 2007; 21: 178-180.

80 Kim JS, Eom Jl, Cheong JW, Choi AJ, Lee JK, Yang WI et al. Protein kinase CK2a as an unfavorable prognostic marker and novel therapeutic target in acute myeloid leukemia. Clin Cancer Res 2007; 13: 1019-1028.

81 Cheong JW, Min YH, Eom Jl, Kim SJ, Jeung HK, Kim JS. Inhibition of CK2a and $\mathrm{PI} 3 \mathrm{~K} /$ Akt synergistically induces apoptosis of $\mathrm{CD} 34^{+} \mathrm{CD} 38^{-}$leukaemia cells while sparing haematopoietic stem cells. Anticancer Res 2010; 30: 4625-4634.

82 Felipe Rico J, Hassane DC, Guzman ML. Acute myelogenous leukemia stem cells: from bench to bedside. Cancer Lett 2013; 338: 4-9.

83 Quotti Tubi L, Gurrieri C, Brancalion A, Bonaldi L, Bertorelle R, Manni S et al. Inhibition of protein kinase CK2 with the clinical-grade small ATP-competitive compound CX-4945 or by RNA interference unveils its role in acute myeloid leukemia cell survival, p53-dependent apoptosis and daunorubicin-induced cytotoxicity. J Hematol Oncol 2013; 6: 78.

84 Quotti Tubi L, Canovas Nunes S, Brancalion A, Doriguzzi Breatta E, Manni S, Mandato $\mathrm{E}$ et al. Protein kinase CK2 regulates AKT, NF-KB and STAT3 activation, stem cell viability and proliferation in acute myeloid leukemia. Leukemia 2017; 31: 292-300.

85 Zhang Y, Zhou SY, Yan HZ, Xu DD, Chen HX, Wang XY et al. miR-203 inhibits proliferation and self-renewal of leukemia stem cells by targeting survivin and Bmi-1. Sci Rep 2016; 6: 19995.

86 Martins LR, Lucio P, Silva MC, Anderes KL, Gameiro P, Silva MG et al. Targeting CK2 overexpression and hyperactivation as a novel therapeutic tool in chronic lymphocytic leukemia. Blood 2010; 116: 2724-2731.

87 Song MS, Salmena L, Pandolfi PP. The functions and regulation of the PTEN tumour suppressor. Nat Rev Mol Cell Biol 2012; 13: 283-296.

88 Carra G, Panuzzo C, Torti D, Parvis G, Crivellaro S, Familiari U et al. Therapeutic inhibition of USP7-PTEN network in chronic lymphocytic leukemia: a strategy to overcome TP53 mutated/deleted clones. Oncotarget 2017; 8: 35508-35522.

89 Rozovski U, Harris DM, Li P, Liu Z, Jain P, Veletic I et al. Constitutive phosphorylation of STAT3 by the CK2-BLNK-CD5 complex. Mol Cancer Res 2017; 15: 610-618.

90 Hazan-Halevy I, Harris D, Liu Z, Liu J, Li P, Chen X et al. STAT3 is constitutively phosphorylated on serine 727 residues, binds DNA, and activates transcription in CLL cells. Blood 2010; 115: 2852-2863.
91 Prins RC, Burke RT, Tyner JW, Druker BJ, Loriaux MM, Spurgeon SE. CX-4945, a selective inhibitor of casein kinase-2 (CK2), exhibits anti-tumor activity in hematologic malignancies including enhanced activity in chronic lymphocytic leukemia when combined with fludarabine and inhibitors of the B-cell receptor pathway. Leukemia 2013; 27: 2094-2096.

92 Martins LR, Lucio P, Melao A, Antunes I, Cardoso BA, Stansfield R et al. Activity of the clinical-stage CK2-specific inhibitor CX-4945 against chronic lymphocytic leukemia. Leukemia 2014; 28: 179-182.

93 Martins LR, Perera Y, Lucio P, Silva MG, Perea SE, Barata JT. Targeting chronic lymphocytic leukemia using CIGB-300, a clinical-stage CK2-specific cellpermeable peptide inhibitor. Oncotarget 2014; 5: 258-263.

94 Jerkeman M, Hallek M, Dreyling M, Thieblemont C, Kimby E, Staudt L. Targeting of B-cell receptor signalling in B-cell malignancies. J Intern Med 2017; doi:10.1111/joim.12600.

95 Heriche JK, Chambaz EM. Protein kinase CK2a is a target for the Abl and Bcr-Abl tyrosine kinases. Oncogene 1998; 17: 13-18.

96 Borgo C, Cesaro L, Salizzato V, Ruzzene M, Massimino ML, Pinna LA et al. Aberrant signalling by protein kinase CK2 in imatinib-resistant chronic myeloid leukaemia cells: biochemical evidence and therapeutic perspectives. Mol Oncol 2013; 7: 1103-1115.

97 Salizzato V, Borgo C, Cesaro L, Pinna LA, Donella-Deana A. Inhibition of protein kinase CK2 by CX-5011 counteracts imatinib-resistance preventing rpS6 phosphorylation in chronic myeloid leukaemia cells: new combined therapeutic strategies. Oncotarget 2016; 7: 18204-18218.

98 Morotti A, Panuzzo C, Crivellaro S, Carra G, Fava C, Guerrasio A et al. BCR-ABL inactivates cytosolic PTEN through casein kinase II mediated tail phosphorylation. Cell Cycle 14: 973-979.

99 Sestero CM, McGuire DJ, De Sarno P, Brantley EC, Soldevila G, Axtell RC et al. CD5-dependent CK2 activation pathway regulates threshold for T cell anergy. J Immunol 2012; 189: 2918-2930.

100 Ferrer-Font L, Villamañan L, Arias-Ramos N, Vilardell J, Plana M, Ruzzene M et al. Targeting protein kinase CK2: evaluating CX-4945 potential for GL261 glioblastoma therapy in immunocompetent mice. Pharmaceuticals 2017; 10: 24

101 Solares AM, Santana A, Baladrón I, Valenzuela C, González CA, Díaz A et al. Safety and preliminary efficacy data of a novel casein kinase 2 (CK2) peptide inhibitor administered intralesionally at four dose levels in patients with cervical malignancies. BMC Cancer 2009; 9: 146.

102 Sarduy MR, García I, Coca MA, Perera A, Torres LA, Valenzuela CM et al. Optimizing CIGB-300 intralesional delivery in locally advanced cervical cancer. $\mathrm{Br} J$ Cancer 2015; 112: 1636-1643.

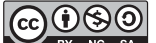

This work is licensed under a Creative Commons AttributionNonCommercial-ShareAlike 4.0 International License. The images or other third party material in this article are included in the article's Creative Commons license, unless indicated otherwise in the credit line; if the material is not included under the Creative Commons license, users will need to obtain permission from the license holder to reproduce the material. To view a copy of this license, visit http:// creativecommons.org/licenses/by-nc-sa/4.0/

(c) The Author(s) 2018 